\title{
The inspection and strength checking of old circular prestressed reinforced concrete pole
}

\author{
Yujing $\mathrm{Hu}^{1, *}$, Xianhui $\mathrm{Cao}^{1}$, Yi Xie ${ }^{1}$, Chao Feng ${ }^{1}$, Sida Wang ${ }^{2}$ and Wei Zhang ${ }^{2}$ \\ ${ }^{1}$ State Grid Hunan Electric Power Company Limited Research Institute, Changsha 410007, China \\ ${ }^{2}$ State Grid Hunan Electric Power Corporation Shaoyang Power Supply Company, Shaoyang 414000, China
}

\begin{abstract}
The capacity expansion of the old transmission lines will lead to an increase in the load level of exsiting prestressed reinforced concrete pole. In this work, the structural parameters of old pole were detected by X-ray imaging technology. The force conditions of the modified concrete pole under the design conditions and actual service conditions were analyzed by Midas/civil. And combined with the calculation of bearing capacity of the circular prestressed reinforced concrete section, the strength checking was conducted. The results showed that X-ray imaging technology can be used to detect the number of steel bars in pole. In addition, the reforming scheme that existing prestressed reinforced concrete poles were used and original LGJ70/10 conductors were replaced with LGJ95/15, still possess considerable safety factor under the actual maximum load conditions.
\end{abstract}

\section{Introduction}

Old low-voltage transmission lines mostly used circular prestressed reinforced concrete pole [1-4]. Since the prestressed poles would not crack during normal service, and the internal steel bars would not easy to corrode [5]. Moreover, the hydration degree of concrete would be more sufficient with the passage of time, so the performance of the old poles would not necessarily decrease. While, the original wires possessing smaller diameter were corroded seriously, which lead to disconnection accidents occurring all the time with the increase of the grid load [6]. In order to save the cost of operation and maintenance, only expanding the capacity of transmission lines and existing prestressed reinforced concrete poles continue to use in the reforming scheme. In this study, it is considered that the performance parameters of poles should be inspected before reconstruction and the strength should be checked after the expansion to ensure that the reforming scheme can meet the force requirements.

\section{Project overview}

The $35 \mathrm{kV}$ Fangwan Line was initially put into operation in October 1999. It was originally operated by a local power company and was later transferred to the State Grid Shaoyang Power Supply Company. The line has a total of 86 base towers, of which No. 1-13 and 23-28 have undergone poles relocation and their wires have been replaced with LGJ-120/20, and the wire grade of other pole sections have adopted LGJ-70/10. During the 2020 Spring Festival power supply period, the Fangwan line was broken twice in 77-78-79 section under high load. It was preliminarily judged that the main reason for the disconnection was the deterioration of mechanical properties of wire due to overload heat. Besides, the $35 \mathrm{kV}$ Fangwan line was planned to be upgraded to a $110 \mathrm{kV}$ line after 2 years.

This reconstruction is aimed at improving the reliability of the power supply of the $35 \mathrm{kV}$ Fangwan Line under high load and saving investment costs at the same time, in condition of upgrade after 2 years. It is planned that the existing poles will be used, the LGJ70/10 wires will be replaced with LGJ95/15 wires, and the matched cross arm, bracing wires and metal fittings will be replaced

The design data have missed and the composition of its prestressed reinforced concrete pole has unknown, due to the Fangwan Line has been built for long years. In addition, the load of the prestressed reinforced concrete pole will change after the wire replaced. It requires inspection and strength checking of old prestressed reinforced concrete pole.

\section{Testing}

By consulting the ledger information of the $35 \mathrm{kV}$ Fangwan Line and combining its fault conditions, the concrete poles with the largest span, the largest corner, the fault ones, and the few concrete poles left after poles relocation (\#31, \#39, \#52, \#62, \#79 respectively) were chosen to conduct on-site inspection and test.

\subsection{Measurement of length, diameter and wall thickness of concrete poles}

The 35kV Fangwan Line has two types of poles, equal-

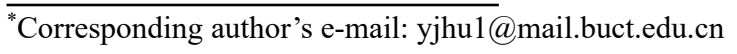


diameter pole and tapered pole. And the height of the \#31, \#39, \#79 concrete poles is measured by the Contour XLRi laser rangefinder, and the $15 \mathrm{~m}$ pole is consist of $9 \mathrm{~m}$ and $6 \mathrm{~m}$ as well as the $18 \mathrm{~m}$ pole is consist of $9 \mathrm{~m}$ and $9 \mathrm{~m}$.

The diameter of the \#31 and \#62 equal-diameter pole was measured by a soft ruler, and their diameter all are 300 $\mathrm{mm}$. And their wall thickness are $60 \mathrm{~mm}$, tested by a vernier caliper. The diameter of the \#39 tapered pole at 3 $\mathrm{m}$ underground is $360 \mathrm{~mm}$. According to the circular reinforced concrete pole (GB 396-1994) and the circular prestressed concrete pole (GB 4623-1994) specification, their tip diameter is $190 \mathrm{~mm}$ and wall thickness is $60 \mathrm{~mm}$.

\subsection{Concrete strength test}

The surface of the on-site reinforced concrete rods was in good condition, and there were no structural cracks, loose layers, honeycombs, pockmarked surfaces and other quality defects. The concrete rebound tester was used to study the concrete strength of the \#31, \#39, and \#79 concrete poles [7], and the results are shown in Table 1.

According to the conversion formula and compared with the technical specification for inspecting of concrete compressive strength by rebound method (JGJT 23-2011), the existing strength is up to C60. Due to the concrete pole would strengthened over time, and C40 or C50 concrete always used in prestressed concrete pole at that time. It can be inferred that concrete poles of the Fangwan Line used C50 concrete.

\subsection{The number of steel bars detection}

The transmission test conducted on the X-ray imaging technology [8] was used to obtain the distribution of steel bars in the circular reinforced concrete poles of Fangwan Line \#62 and \#52. The circular reinforced concrete samples are detected by the partition reconstruction method, and the radiographic detection parameters are 270 $\mathrm{kV} / 20$ pulses.

The typical image is shown in Figure 1. According to the results, \#62 equal-diameter pole are equipped with 20 longitudinal prestressed steel bars, and \#52 tapered poles are loaded with 26 longitudinal prestressed steel bars.

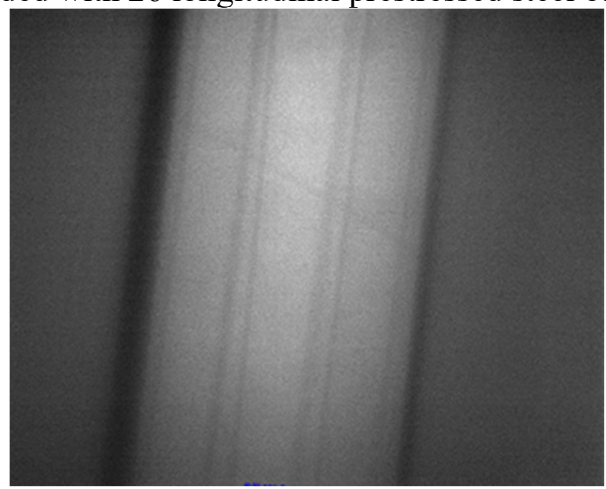

Figure 1. Typical radiographic inspection image of circular pole.

\subsection{Steel bars strength test}

Three steel bars with a length of $200 \mathrm{~mm}$ were cut from the remaining equal-diameter poles after pole relocation. There are no corrosion in the steel bars. Then, mechanical tensile properties of steel bars were investigated, and their strength were 1598.2 $\mathrm{MPa}, 1606.8 \mathrm{MPa}$ and $1582.5 \mathrm{MPa}$, all exceeding $1570 \mathrm{MPa}$. The test results are shown in Table 1. Combined with the conventional design, it can be known that the line tower consist of prestressed reinforced concrete.

\section{Calculation of bearing capacity of circular prestressed reinforced concrete pole}

\subsection{Material parameters}

The material parameters are shown in Table 1.

Table 1. Parameters of steel bars and concrete.

\begin{tabular}{|c|c|c|}
\hline Symbol & Material parameters description & Parameters value /Mpa \\
\hline fptk & Prestressed reinforced strength standard value & 1570 \\
\hline fpy & Prestressed reinforcement tensile strength design value & 1070 \\
\hline f'py & Prestressed reinforcement compressive strength design value & 400 \\
\hline $\mathrm{fcm}$ & The design value of mean compressive strength of concrete & 26 \\
\hline ftk & The standard value of axial tensile strength of concrete & 2.75 \\
\hline Es & Modulus of elasticity of reinforced & $2.0 * 105$ \\
\hline Ec & Elastic modulus of concrete & $3.45 * 104$ \\
\hline $\mathrm{f}^{\prime} \mathrm{cu}$ & A side length of $150 \mathrm{~mm}$ concrete cube compressive Strength of the construction phase & 35 \\
\hline
\end{tabular}

\subsection{Calculation of geometric parameter}

(1) Tapered pole. Cross section of concrete pole at a depth of $3 \mathrm{~m}$ : Outer radius: $r_{2}=180 \mathrm{~mm}$ Inner radius: $r_{1}=180-60=130 \mathrm{~mm}$
Cross-sectional area: $\mathrm{A}=\pi^{*}\left(\mathrm{r}_{2}^{2}-\mathrm{r}_{1}^{2}\right)=56548 \mathrm{~mm}^{2}$ $\mathrm{mm}^{2}$

Cross-section of steel: $A_{p}=n * \pi / 4 * D^{2}=\pi / 4 \times 52 \times 26=510$

(2) Equal-diameter pole.

Cross section of concrete pole at a depth of $3 \mathrm{~m}$ :

Outer radius: $\mathrm{r}_{2}=150 \mathrm{~mm}$

Inner radius: $r_{1}=150-60=90 \mathrm{~mm}$ 
Cross-sectional area: $A=\pi^{*}\left(\mathrm{r}_{2}^{2}-\mathrm{r}_{1}^{2}\right)=45238 \mathrm{~mm}^{2}$

Cross-section of $\mathrm{A}_{\mathrm{p}}=\mathrm{n} * \pi / 4 * \mathrm{D}^{2}=\pi / 4 \times 52 \times 20=392.7 \mathrm{~mm}^{2}$

\subsection{Calculation of tension control stress}

The circular prestressed reinforced concrete poles were made by post-tensioning method, and the tensile control stress should calculated by 0.7 times of the prestressed reinforced strength standard value $\left(\mathrm{f}_{\text {ptk }}\right)$, as follows.

$\sigma_{\text {con }}=0.7 \mathrm{f}_{\mathrm{ptk}}=0.7 \times 1570=1099 \mathrm{Mpa}(1)$

\subsection{Calculation of prestress loss}

Post-tensioning prestress loss is as follows.

Loss caused by anchorage deformation and steel retraction.

$$
\sigma_{l 1}=\frac{\alpha}{L} E_{S}=22 \mathrm{~N} / \mathrm{mm}^{2}
$$

Loss caused by temperature difference.

$$
\sigma_{l 2}=2 \Delta t=40 \mathrm{~N} / \mathrm{mm}^{2} \text { (3) }
$$

(3) Loss caused by reinforcement relaxation.

$$
\sigma_{l 4}=\psi\left(0.36 \frac{\sigma_{c o n}}{f_{p t k}}-0.18\right)=71 \mathrm{~N} / \mathrm{mm}^{2}
$$

(4) Loss caused by concrete shrinkage and creep. For tapped pole:

$\sigma_{l 5}=\left(45+\frac{220 \sigma_{p c 1}}{f_{c u}^{\prime}}\right) /(1+15 \rho)=85 \mathrm{~N} / \mathrm{mm}^{2}$

Similarly, for equal-diameter pole:

$$
\sigma_{l 5}=97 \mathrm{~N} / \mathrm{mm}^{2}
$$

\subsection{Calculation of effective prestress}

The formula of effective prestess is as follows:

$$
\sigma_{p c}=\sigma_{c o n}-\sigma_{l I}-\sigma_{l I I}=\sigma_{c o n}-\left(\sigma_{l 1}+\sigma_{l 3}+\sigma_{l 4}\right)-\sigma_{l 5}(7)
$$

Effective prestress of equal-diameter pole:

$$
\sigma_{p c 1}=883 \mathrm{~N} / \mathrm{mm}^{2}(8)
$$

Effective prestress of equal-diameter pole:

$\sigma_{p c 1}=871 \mathrm{~N} / \mathrm{mm}^{2}$

\subsection{Capacity calculation of prestressed reinforced concrete normal section}

According to Specifcations for Design of concrete structures (GBJ10-89), the capacity calculation formula of prestressed reinforced concrete normal section is as follows.

$$
\begin{aligned}
& M_{p}=K[M]=\frac{1}{\pi}\left[\begin{array}{l}
\left(\mathrm{f}_{c m} A \frac{r_{1}+r_{2}}{2}+\mathrm{f}_{\mathrm{py}} A_{p} r_{p}\right) \sin \pi \alpha \\
+\left(\mathrm{f}_{p y}-\sigma_{p c}\right) A_{P} r_{p} \sin 1.5 \pi \alpha
\end{array}\right]_{(10)} \\
& \alpha=\frac{f_{y} A_{P}}{f_{c m} A+\left(1.5\left(f_{p y}-\sigma_{p c}\right)+f_{p y}^{\prime}\right) A_{p}}(11)
\end{aligned}
$$

Therefore, the design value of section bending moment of equal-diameter pole is as follows.

$$
\alpha=0.2896, \mathrm{M}=74.20 \mathrm{kN} * \mathrm{~m}(12)
$$

And for tapped pole, the design value of section bending moment is as follows.

$$
\alpha=0.3, \mathrm{M}=110.11 \mathrm{kN} * \mathrm{~m}(13)
$$

\section{The bearing capacity checking of concrete poles}

For tensile poles, the bracing wire can balance the horizontal load of the tower head, which lead to the bending moment at the root of the tower is small, and the strength of the tower will not become a control condition. Therefore, only the straight pole without bracing wire were checked.

\subsection{Calculation of the most adverse working condition}

\subsubsection{Tower}

The tower structure is shown in Figure 2. The reinforced concrete pole has a full height of $18 \mathrm{~m}$, an upper section of $9 \mathrm{~m}$ and a lower section of $9 \mathrm{~m}$, with the underground part at $3 \mathrm{~m}$ depth. According to the distribution span of Fangwan Line, the typical horizontal span is $200 \mathrm{~m}$ and vertical span elect to $300 \mathrm{~m}$. Parameters of replaced wire and ground wire are shown in Table 2. The internal force of poles is often controlled by normal strong wind conditions. On the basis of the design weather conditions which provided by the Wugang area of Fangwan Line of Shaoyang Institute, the most adverse working conditions are designed as temperature at $-5{ }^{\circ} \mathrm{C}$, wind speed of 25 $\mathrm{m} / \mathrm{s}$, and ice coating with $0 \mathrm{~mm}$. The weight of metal fitting of wire is $300 \mathrm{~N}$, and the metal fitting weight of ground wire is $90 \mathrm{~N}$.

Table 2. Parameters of replaced wire and ground wire.

\begin{tabular}{|c|c|c|}
\hline Parameters & Replace wire & Ground wire \\
\hline Type & LGJ-95/15 & GJ-35 \\
\hline Cross-sectional area $/ \mathrm{mm}^{2}$ & 109.72 & 50 \\
\hline Outside diameter/mm & 13.61 & 8.7 \\
\hline Dead load, g1 & 34.04 & 84 \\
\hline Icing load, g2 & 23.52 & 39.24 \\
\hline $\begin{array}{c}\text { Total vertical specific } \\
\text { load, g3 }\end{array}$ & 57.55 & 123.25 \\
\hline Wind load without ice, g4 & 48.47 & 50.17 \\
\hline $\begin{array}{c}\text { Comprehensive load } \\
\text { under wind without ice,g5 }\end{array}$ & 59.22 & 97.88 \\
\hline
\end{tabular}




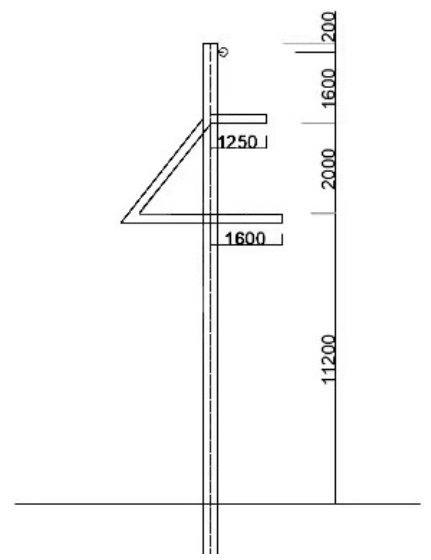

Figure 2. Schematic diagram of the tower structure.

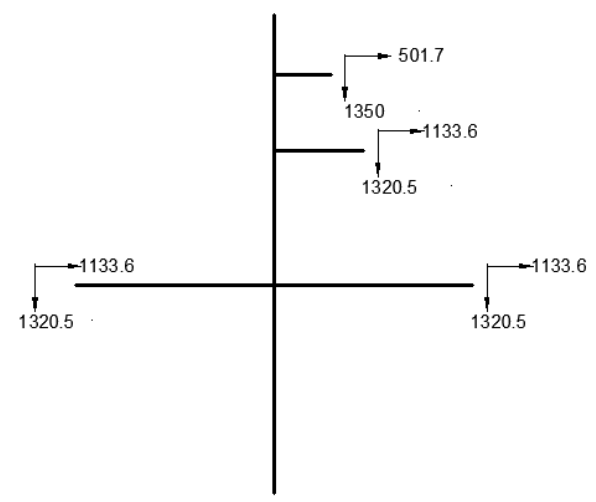

Figure 3. Schematic diagram of tower head load when the wire adopts LGJ-95/15.

The schematic diagram of tower head load of which the wire is replaced with LGJ-95/15. Load calculation results are present in Table 3, and the schematic diagram is shown in Figure 3. The beam element is used to establish the finite element calculation model after the wire replacement, as shown in Figure 4. In the calculation of depth, tower has $1 \mathrm{~m}$ underground, and the bottom of the pole is consolidated.

Table 3. Calculation of each hanging point of tower head

\begin{tabular}{|c|c|c|}
\hline Load type & Formula & $\begin{array}{c}\text { Load } \\
\text { value/N }\end{array}$ \\
\hline $\begin{array}{c}\text { Ground vertical load, } \\
\mathrm{Gb}\end{array}$ & $g_{1 b} * S * L_{V}+G_{j b}$ & 1350 \\
\hline $\begin{array}{c}\text { Ground horizontal wind } \\
\text { load, Pb }\end{array}$ & $g_{4} * S * L_{H}$ & 501.7 \\
\hline $\begin{array}{c}\text { Current wire vertical } \\
\text { load, Gb }\end{array}$ & $g_{1 d} * S * L_{v}+G_{j d}$ & 1320.46 \\
\hline $\begin{array}{c}\text { Current wire horizontal } \\
\text { wind load, Pb }\end{array}$ & $g_{4 d} * S * L_{H}+P_{j d}$ & 1133.63 \\
\hline
\end{tabular}

Wind pressure on pole: $\mathrm{q}=25^{\wedge} 2 / 1.6^{*} 0.6^{*} 0.3=71 \mathrm{~N} / \mathrm{m}$.

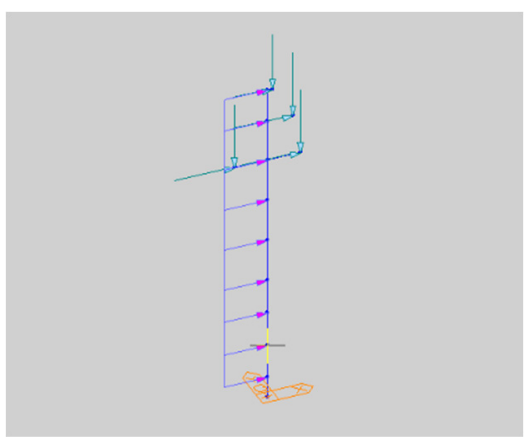

Figure 4. The finite element model of the tower structure.

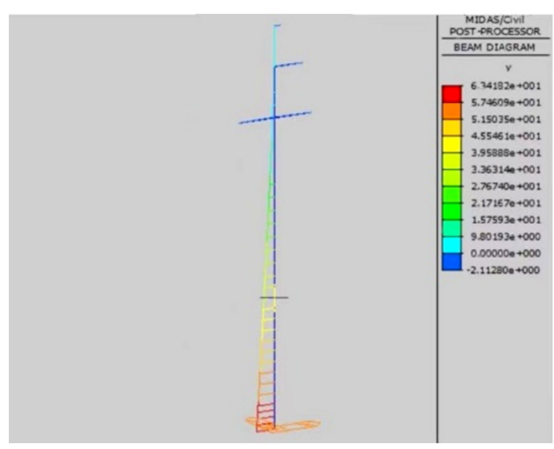

Figure 5. The internal force of the tower structure under strong wind conditions.

It can be seen from Figure 5 that the maximum of calculated bending moment of the pole root is $63.42 \mathrm{kN} * \mathrm{~m}$ when using LGJ-95/15 wire.

The design value of section bending moment of $300 \mathrm{~m}$ equal-diameter pole is $\mathrm{M}=74.20 \mathrm{kN}^{*} \mathrm{~m}$, and the design value for tapped pole is $\mathrm{M}=110.11 \mathrm{kN} * \mathrm{~m}$, elucidated in the section 3.6. Although the design value all greater than the calculated maximum bending moment under strong wind conditions, the value fail to meet the standard for the safety factor of prestressed concrete members above 1.8 .

\subsection{Calculation of the most adverse conditions in actual operation}

Wugang Meteorological Bureau provides the information of maximum wind speed in the area where the line is located, and the maximum monthly wind speed is $4-10$ $\mathrm{m} / \mathrm{s}$. At the same time, the operation and maintenance personnel reported that the line hardly ever covered by ice in the winter and spring over the years, and the maximum ice thickness would not exceed $5 \mathrm{~mm}$. Therefore, the condition of ice coating with $5 \mathrm{~mm}$ and wind speed with $10 \mathrm{~m} / \mathrm{s}$ was regarded as the most adverse operating conditions. The load calculation results in ice-coated and windy condition are present in Table 4 , and the schematic diagram is shown in Figure 6.

Table 4. Load calculation of each hanging point of ice-coated and windy tower head

\begin{tabular}{|c|c|c|}
\hline Load type & Formula & Load value/N \\
\hline $\begin{array}{c}\text { Ground vertical load, } \\
\mathrm{Gb}\end{array}$ & $g_{1 b} * S * L_{V}+G_{j b}$ & 1938.7 \\
\hline $\begin{array}{c}\text { Ground horizontal } \\
\text { wind load, } \mathrm{Pb}\end{array}$ & $g_{4} * S * L_{H}$ & 282.5 \\
\hline
\end{tabular}




\begin{tabular}{|c|c|c|}
\hline $\begin{array}{c}\text { Current wire vertical } \\
\text { load, Gb }\end{array}$ & $g_{1 d} * S * L_{v}+G_{j d}$ & 2094.32 \\
\hline $\begin{array}{c}\text { Current wire } \\
\text { horizontal wind load, } \\
\mathrm{Pb}\end{array}$ & $g_{4 d} * S * L_{H}+P_{j d}$ & 417.37 \\
\hline
\end{tabular}

Wind pressure on pole: $\mathrm{q}=10^{\wedge} 2 / 1.6^{*} 0.6^{*} 0.3=11.25$ $\mathrm{N} / \mathrm{m}$

It can be seen from Figure 7 that the maximum calculated bending moment of the root of pole is $\mathrm{W}=25.08$ $\mathrm{kN} * \mathrm{~m}$ in ice-coated and windy condition when LGJ-95/15 wire is used. The design value of section bending moment of $300 \mathrm{~m}$ equal-diameter pole is $\mathrm{M}=74.20 \mathrm{kN} * \mathrm{~m}$, and the design value for tapped pole is $\mathrm{M}=110.11 \mathrm{kN} * \mathrm{~m}$, both of which have a safety factor of more than 2 times.

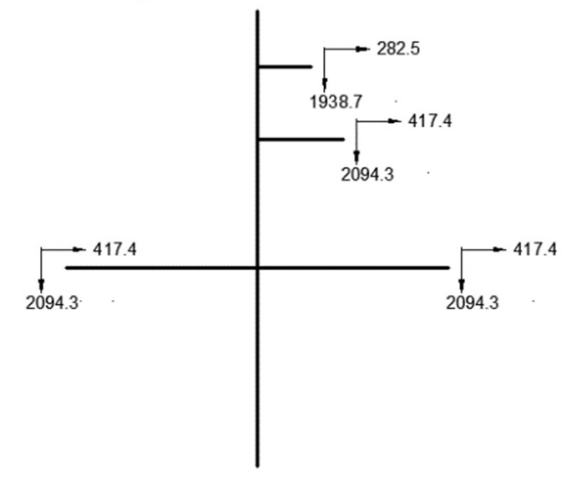

Figure 6. Tower head load when LGJ-95/15 is used for the wire (ice-coated and windy).

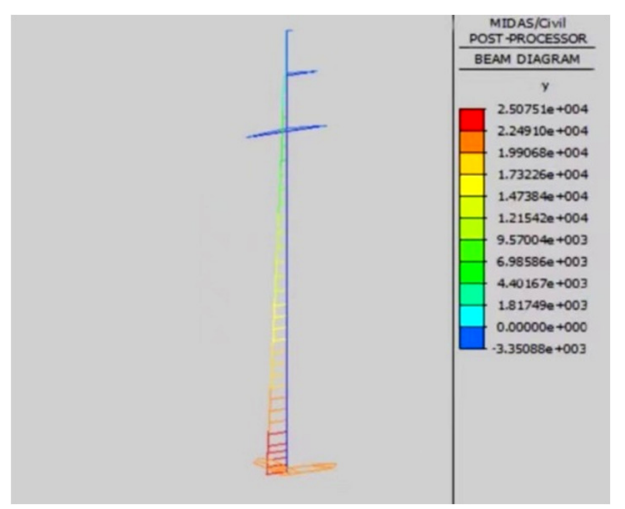

Figure 7. The internal force of the tower structure under icecoated and windy conditions.

\section{Conclusion}

The circular prestressed reinforced concrete poles of the Fangwan Line were tested and the strength was checked, and the following conclusions were obtained:

1) X-ray imaging technology can be used to detect the number of reinforcement in circular poles.

2) In this reforming scheme, original LGJ70/10 wire was replaced with LGJ95/15 wires and existing prestressed reinforced concrete poles are used. Then, the load level is increased. And by strength checking, it still has a safety factor of 2 times under the most adverse conditions in actual operation. It shows that the scheme is feasible and effective.

\section{References}

1. Siyuan Liu, Kaiquan Xia. Evaluation Method for Concrete Pole Safety of Overhead Transmission Line [J]. Electric Power, 2013,46(01):65-68..

2. Xila Liu, Guojing Zhang. Non-linear analysis of prestressed centrifugal concrete power pole with ringshaped cross section [J]. China Civil Engineering Journal, 1981(04):31-40.

3. Pinwu Guan, Li Li, Lixin Liu, Yan Zhang. Ultimate Capacity and Deflect Analysis of High-strength Prestressed Concrete Electricity Poles [J]. Journal of Zhengzhou University (Engineering Science), 2000(03):64-67.

4. Oliphant W J, Sherman D C. Prestressed concrete transmission pole structures (recommended practice for design and installation) $\|$ foundations [J]. American Society of Civil Engineers, 2012:85-100.

5. Yushu Lei. Research on longitudinal crack of ring cross section prestressed concrete poles [J]. China Civil Engineering Journal, 1994(03):59-66.

6. Wenna Zhang, Yanyun Yan, Zhifeng Li, Huafeng Zhao, Xiaojian Wang. Analysis and Countermeasures of Lightning Trip-out Failure on Overhead Transmission Line [J]. Electrical Engineering, 2014(04):100-103.

7. Weihang Pan. Study on Comprehensive Method of ultrasonic and rebound Strength Testing of Concrete and its effect Factors [J]. Concrete, 2002(08):24-25.

8. Jiarui Hu, Chun Liu, Kejian Ouyang, Yi Xie, Junjun Chen. Detection Technology on Longitudinal Cracks of Concrete Pole [J]. North China Electric Power, 2014(10):33-35+60. 